\title{
Marine and Coastal Information Systems for Europe and Africa
}

\author{
Nicolas Hoepffner, Marco Clerici, and Andrea Marelli \\ European Commission - Joint Research Centre. Institute for Environment and Sustainability \\ I-21027 Ispra (Va), Italy. Nicolas.hoepffner@jrc.ec.europa.eu
}

\begin{abstract}
Marine Information Systems for Europe (EMIS, http://emis.jrc.ec.europa.eu/) and Africa (AMIS, http://amis.jrc.ec.europa.eu/) have been recently developed at the Joint Research Centre of the European Commission to provide the Users with an appropriate set of biophysical information, of importance to conduct water quality assessment, resource monitoring and climate change studies in the coastal and marine waters. These are simple and easy-to-use mapping tool applications, created for the publication and dissemination of African marine information via the web. Both systems rely mostly on Earth Observation data from optical and thermal sensors, processed according to standard (i.e., space agency-related) and in-house peer-reviewed algorithms, as well modeled data to generate indicators for global diagnostic of the coastal state and analyses of changes in marine ecosystems. In addition, the systems supply the users with basic navigation and interrogation tools with a range of time-series and statistical analysis generated automatically in a format ready for publication / reporting, and enabling decision makers to make full and lasting use of this information.

In this work, we review the different features of the systems through case studies such as marine eutrophication in Europe, coastal productivity in Eastern Africa, and their evolution with time.
\end{abstract}

Keywords: Marine information system, satellite data, coastal indicators.

\section{Introduction}

Rapid and often negative changes of the water quality, and subsequent degradation of marine habitats over the continental shelves have highlighted the necessity to develop strong political instruments that would preserve the natural resources and biodiversity, while keeping the related economic sectors viable. The success of implementing these policies depends on the nature and reliability of the scientific data, the aggregation of these data into appropriate information (so-called indicators) maps, but also on the degree of harmonization in the methods and monitoring tools, and on the frequency to which this information can be made available with respect to the time variability of marine processes.

Systematic assessment of the marine and coastal environment using in situ techniques remains a valuable approach, albeit costly, to support an effective management programme at local or regional level. Observations from satellite can however provide an additional dimension and a cost-effective way to capture the main processes like sediment transport, coastal upwelling, eutrophication, that can modify the water properties at scale ranging from hours to several days and more.

In spite of the great potential of satellite data to achieve unprecedented instant examination of the global ocean and coastal areas, several constraints have been identified by the community to use these data operationally, particularly in developing countries. These constraints are specifically the access to data and an inadequate analysis and information dissemination approaches to communities outside the research / scientific system. Over the last decade, tools to handle geographical or spatial data have 
evolved rapidly, becoming very useful in the study of marine ecosystems, integrating various aspects such as database creation, monitoring, mapping and visualization. Geographical Information Systems (GIS), for example, enable the combination of data from multiple and disparate sources, as well as provides an excellent platform to communicate results of scientific studies to a wider community including the policy makers.

In this work, we review through case studies the different features of Marine Information Systems which were recently setup for European seas and African coastal waters to support EU's sustainable development strategy (CEC 2001). Both systems provide the user community at large with an appropriate set of bio-physical information, of importance to conduct water quality assessment and resource monitoring in the coastal and marine waters.

\section{Information Systems Design and Architecture}

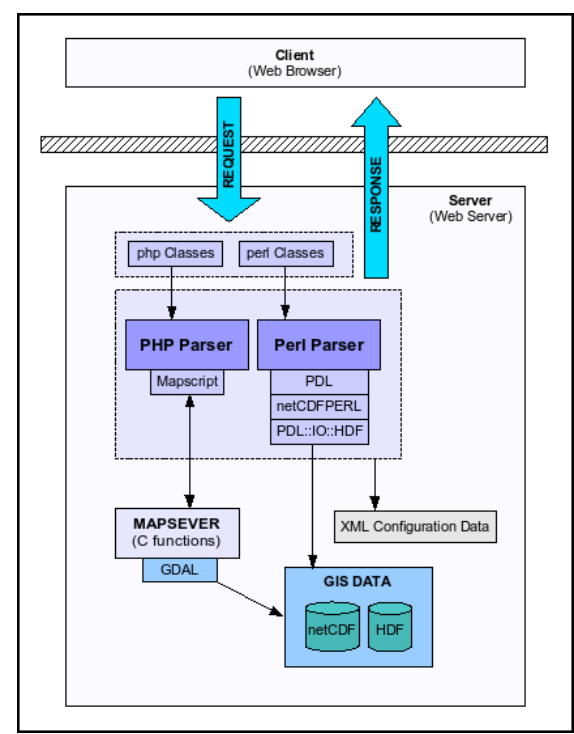

The information systems for Europe (EMIS; http://emis.jrc.ec.europa.eu/) and for Africa (AMIS; http://amis.jrc.ec.europa.eu/) are web-Geographical Information Systems (GIS) based on a UMN MapServer engine (http://mapserver.org/), originally developed for building spatially-enabled internet applications (Vatsavai et al. 2006). It is written in HTML 4.01 Transitional codes, and uses PHP Hypertext Preprocessor tools.

Figure 1: Technical workflow of both systems. Requests from users are sent to the Web-server with all information concerning the map that needs to be displayed (e.g. dimensions, extension, layers). The Web-server then calls the PHP functions responsible for creating the new map. The PHP parser executes the code and uses MapServer functions to retrieve the geographical data, create the map and save on the server.

\section{System Functionalities}

Systems'operations include i) the provision of continuous, detailed and accurate information on relevant marine biophysical parameters as derived from optical, and infrared satellite sensors; ii) the generation of indicators (primary productivity, features seasonal timing) for global diagnostic of the coastal state and analyses of changes in marine ecosystems; iii) the optimization and implementation of an interdisciplinary system of marine resources information and analysis (GIS) in order to enable decision makers to make full and lasting use of this information for management purposes.

The GIS functionalities of the systems enable the visualization and analysis of a variable through the following steps: variable selection, map navigation, identification of region of interest (pixel or geographical windows) and data analysis. Basic statistics include the mean, minimum and maximum values, and the standard deviation of the selected variable. An arithmetic or geometric mean is calculated according to the type of distribution of the variable (i.e., normal or log-normal distribution). To avoid outlier pixels in the calculation of the statistics, a two-step 'pixel filtering' is applied to the data. That process is rejecting from the calculation all values outside a distance of 2 times the standard deviation around the mean. 
Among other statistical features, a threshold analysis allows the display of values within a selected range only. Correlation analysis can be made between two selected variables, resulting in a scatter plot or a $2 \mathrm{D}$ density plot depending on whether the total number of sampled pixels is lower or larger than 5000. Finally, time series and inter-annual monthly variability analysis can be performed on a selected marine property. The resulting time series plot presents the evolution of the annual mean and its standard deviation, as well as the evolution of the minimum and maximum values.

For each analysis performed, the results are reported in the 'display' area and values can be exported in ASCII file, while figures (maps and plots) can be saved as 'pdf' files.

\section{System Datasets}

The systems rely mostly on satellite and modelled data. Satellite products from optical radiometry and thermal imagery are retrieved using standard (i.e., issued from space agencies) and in-house peer-reviewed algorithms, which have been implemented in a fully operational processing chain for applications in African waters and European seas. At present, the satellite products are based on imagery from the Coastal Zone Color Scanner (CZCS; Feldman et al. 1989), the Sea-viewing Wide Field-of-View Sensor (SeaWiFS; McClain et al. 1998), and the Moderate resolution Imaging Spectrometer (MODIS-Aqua). SeaWiFS and MODIS ensure unbroken observations of the marine environment since 1997. On the other hand, long-term changes in marine properties can be analyzed by comparing climatological SeaWiFS - MODIS data against data from CZCS period (19781986), recently re-processed for better consistency with the other two sensors (Antoine et al. 2005). Other satellite sensors include the Advanced Very High Resolution Radiometer (AVHRR) Pathfinder series (Kilpatrick et al. 2001) granting a time series of sea surface temperature since 1985 . The data set consists of monthly composites covering the domain $40^{\circ} \mathrm{N}-50^{\circ} \mathrm{S}, 30^{\circ} \mathrm{W}-60^{\circ} \mathrm{E}$, around Africa at a spatial resolution of $4 \mathrm{~km}$; and $65^{\circ} \mathrm{N}-30^{\circ} \mathrm{N}, 13^{\circ} \mathrm{W}-42^{\circ} \mathrm{E}$ for European seas at a spatial resolution of $2 \mathrm{~km}$.

An important marine information monitored by satellite is the concentration of chlorophyll (O'Reilly et al. 2000), an omnipresent pigment in all phytoplankton species and, for this reason, commonly used as an index of phytoplankton biomass. In marine and coastal waters, phytoplankton biomass and associated primary production are descriptors of the first trophic level in the marine food chain. Their quantitative estimates from satellite provide important information on the structure and functioning of the rest of the food web up to commercially exploited fish populations. Water productivity or primary production is calculated using a full wavelength-resolved, depth-resolved model as described by Platt and Sathyendranath (1988) and implemented by Longhurst et al. (1995) at global scale. The diffuse attenuation coefficient in the green part of the spectrum, $K_{d}(490)$, is also a standard optical product from satellite ocean colour (Mueller 2000). It reflects the degree of light penetration in the water column and, thus, represents a good indicator of the water clarity or transparency.

For European seas, several physical and biological variables are used to derive some indices characterizing the key processes occuring at the surface and the seabed, which play an essential role in the vulnerability of a specific environment to eutrophication and hypoxia. These indices are the 'Physical Sensistive Area' (PSA) index and the 'OXYgen depletion RISK' (OXYRISK) index (Druon et al. 2004). PSA index integrates all physical factors controlling eutrophication with the aim to locate sensitive areas to oxygen deficiencies assuming primay production and nutrients evenly distributed in that area. OXYRISK index provides information on the spatial distribution of potential hypoxia for a given month by performing an oxygen budget between the physics (source term) and the flux of organic matter (sink term) represented as the satellite-derived chlorophyll concentrations or primary production. 
Physical variables are generated by a 3-D hydrodynamic model, GETM (General Estuarine Transport Model; http://www.getm.eu/), described in details by Burchard and Bolding (2002). GETM includes flexible vertical and horizontal coordinate systems, enabling applications in shallow coastal environments. The model also benefits from an accurate turbulence parameterization scheme through its coupling with GOTM, General Ocean Turbulence Model (Burchard 2002). The model is consistently implemented in all European seas and has been validated in the North Sea (Stips et al. 2004), the Black Sea (Peneva and Stips 2005), selected sub-basins of the Mediterranean Sea (Garcia-Gorriz and Stips 2006), and the Baltic Sea (Miladinova and Stips 2010).

\section{Vulnerability of European Seas to Eutrophication}

Marine eutrophication is considered a major environmental issue in Europe (EEA, 2000), causing various biological effects such as green tides, anomalous phytoplankton blooms, deep-water anoxia and fish population changes. The increase in nutrients at the coast results in an escalation in photosynthesis and production of organic matter, which in turn can reduce the water transparency and oxygen availability at depth, causing irreversible loss of habitats and mortality of benthic organisms (van Katwijk et al. 2010). Different shallow marine ecosystems have a strongly disparate physical resistance to eutrophication which must be taken into account when assessing the effort for restoration. Assuming that phytoplankton growth is largely conditioned by the local physical conditions, the sensitivity of a coastal system to eutrophication can be evaluated from numerical modelling and a limited set of physical parameters describing the surface processes and the bottom physics.

In the PSA index (fig. 2), the advection and stratification define the surface physics, representing respectively the horizontal transport and diffusion of nutrients from a point source, and the retention of phytoplankton organisms in the productive euphotic layer. Adding the bottom diffusivity to the other two processes gives an indication of the oxygen renewal capacities near the sea bottom, considering an oxygen reserve that depends on the bottom temperature and salinity and the water mass just above.

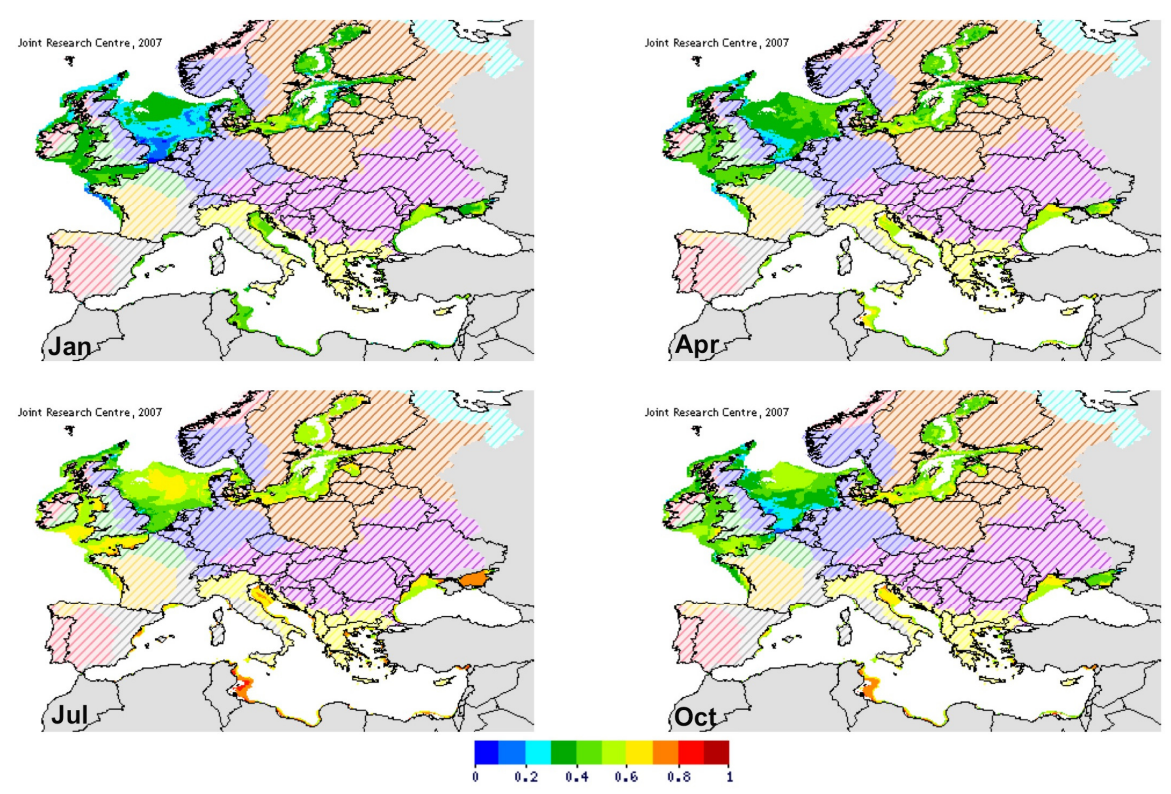

Figure 2: Monthly maps of the modeled Physical Sensitive Area (PSA) index for European seas (< 100m water depth) from 10-years climatology (1998-2008). The index ranges from 0 to 1 reflects the vulnerability of the coastal waters to eutrophication based on the 
dominant physical processes. Additional data layer on land illustrates the catchment basins.

In most cases, higher stratification during summer contributes to increase the level of sensitivity of coastal waters to eutrophication. However, the seasonal variability of PSA index remains low in enclosed seas such as the Baltic, with values ranging from 0.4 to 0.57 during summer months. In the North Sea, especially the southern North Sea, and to some extent in the Channel, strong tidal currents would tend to keep the area resistant to eutrophication.

The OXYRISK index (fig.3) indentifies the most probable occurrence of oxygen deficiency at the bottom in shallow areas due to the degradation of organic matter. Phytoplankton is considered as the main source of production and export of organic matter. The monthly load of organic matter produced in the upper layers is exported horizontally within the mixed layer according to the monthly mean advection from GETM, and vertically using a constant sinking velocity. A degradation rate of the particulate organic matter (POM) in the water column $\left(0.075 \mathrm{~d}^{-1}\right)$ is applied to take into account the higher deposition rate in shallower waters compared to deeper waters. In order to evaluate the risk of hypoxia, the oxygen consumption is compared to the oxygen reserve and renewal during the growing season.

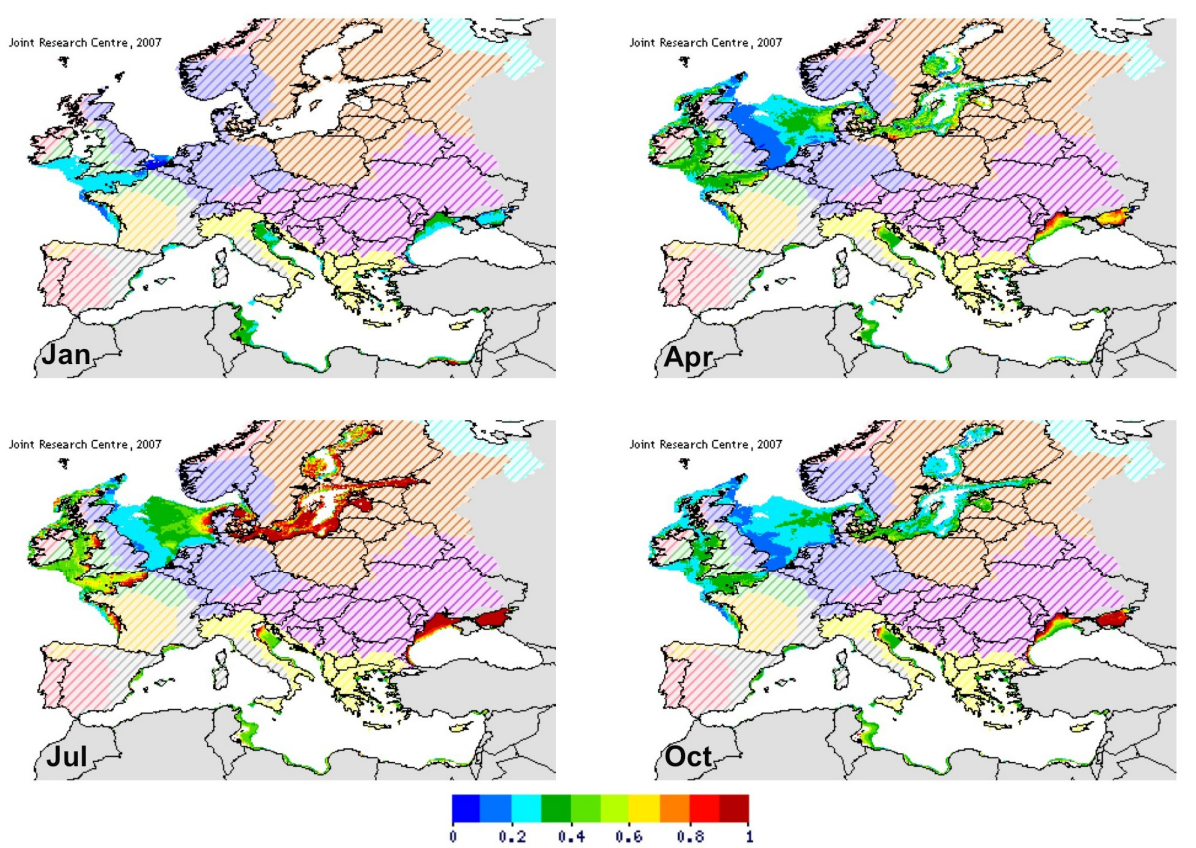

Figure 3: Monthly maps of the modeled Oxygen depletion Risk (OXYRISK) index for European seas (<100m water depth) from 10-years climatology (1998-2008). The index ranges from 0 to 1 reflects the probability to have bottom hypoxia considering the physical processes at depth and the biomass production in the upper layers. Additional data layer on land illustrates the catchment basins.

Note that the processing of satellite-based optical data can be limited by cloud cover, sea ice, or low sun zenith angle. As a result, a low level of valid pixels can be accounted for in the estimation of OXYRISK index in winter in the northern European seas. Eventhough most of the phytoplankton biomass production occur during spring, OXYRISK maximum values in summer results from the decrease of both the oxygen reserve (due to lower saturation) and the renewal capacity of isolated water masses. The southern Baltic and northwestern Black Sea have higher risk of hypoxia during summer. 


\section{Seasonal productivity in African coastal waters}

With ca. $63000 \mathrm{~km}$ of coastline and an estimated shelf area (depth 0-200 m) of 987.000 $\mathrm{km}^{2}$, coastal fisheries represent an important sector of Africa's economy. This economy, however, is closely related to the state of the surrounding environment and natural resources. The distribution of fish is highly vulnerable to climatic fluctuations, and the establishment of an adequate environmental monitoring system is compulsory for the development and implementation of strategies to ensure a sustainable control of the resource.

Atmospheric features, winds, and their seasonality produce complex oceanographic features, especially coastal upwelling along the coast. These physical changes directly affect primary production processes but also may be expected to influence the abundance, distribution and diversity of other organisms dependent upon that production. The tool AMIS makes possible the analysis of time series for various environmental variables of importance to the management of marine resources.

The north-western African coast (from Morocco to Senegal) is one of the four major upwelling areas of the world ocean. This oceanographic feature yields optimal conditions to sustain growth of organisms at all level of the food chain. Off Mauritania (fig.4), upwelling is a seasonal feature responsible for periodical changes in the population of some pelagic fishes, e.g. sardines (or sardinella) alternating with species of anchovy or mackerel, while other species remain permanently in the area.

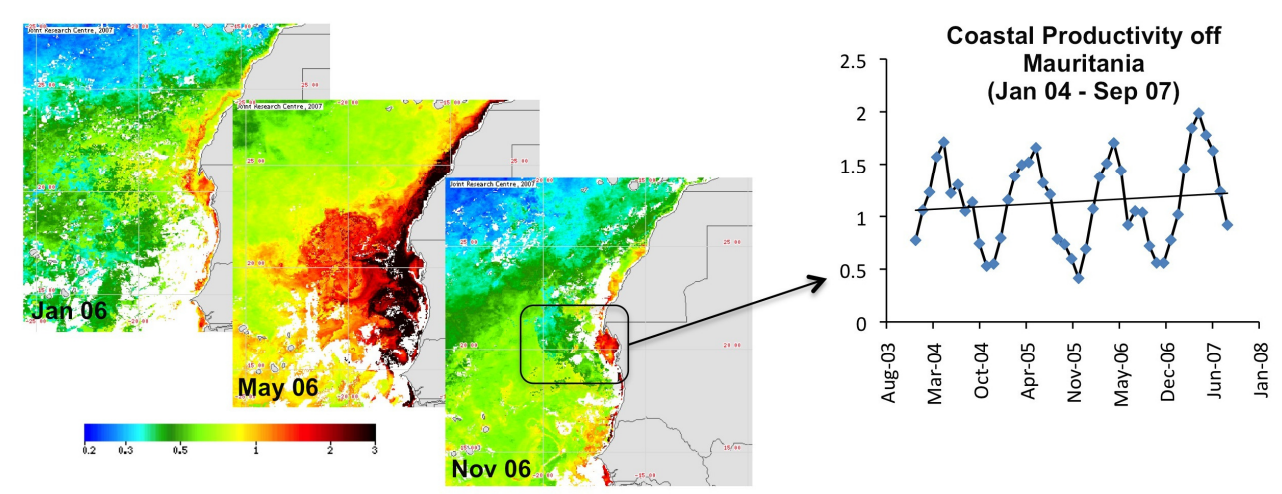

Figure 4: Coastal water productivity (primary production, in $g C \cdot m^{-2} \cdot d^{-1}$ ) off the coast of Mauritania as retrieved from ocean colour radiometry monthly composites in January, May and November 2006 (MODIS imagery). Right panel: interannual variability and trend of the upwelling seasonal event off Cape Blanc (adapted from AMIS data, http://amis.jrc.ec.europa.eu/).

Climatic factors such as temperature, wind stress and wind direction can affect significantly the upwelling strength (McGregor et al. 2007), creating some changes at all levels of the food chain and disturbing this alterning pattern of abundance between fish species. Previous studies conducted in these waters have shown significant correlation between spawning of several major fish species and the upwelling process (Roy and Reasons 2001). The interannual variations of the upwelling is related to the abundance of the fish stock, suggesting the need for some environmental features to be included as an independent variable in fishery models in addition to the solely fishing effort (or catch per unit effort).

\section{Conclusions}

Remotely-sensed data provides information to calculate objective ecosystem indicators that can be applied in operational mode as an aid to coastal management. As time series 
extend, the information will improve and become more widely available to the community at large. EMIS and AMIS are simple and easy-to-use mapping tool application, developed for the publication and dissemination of marine and coastal information via the web. Their applications range from water quality management, monitoring issues that can impact on the ecosystems and resource distribution to climate studies, examining interactions between marine resources and major forcing variables. Both systems are fast and simple, resulting in a very practical and useful high level user application.

\section{References}

Antoine D., A. Morel, H.R. Gordon, V.F. Banzon, and R.H. Evans, 2005. Bridging ocean color observations of the 1980's and 2000's in search for long term trends. J. Geophys. Res., 110: C06009, doi:10.1029/2004JC002620.

Burchard H., and K. Bolding, 2002. GETM, A General Estuarine Transport Model, Scientific Documentation. European Commission technical report, EUR 20253 EN

Druon J-N., W. Schrimpf, S. Dobricic, and A. Stips, 2004. Comparative assessment of large-scale marine eutrophication: North Sea area and Adriatic Sea as case studies. Marine Ecology Progress Series , 272, 1-23.

CEC, 2001. A sustainable Europe for a better world: A European Strategy for Sustainable Development. European Commission Communication, COM(2001) 264 final.

EEA, 2000. Nutrients in European Ecosystems. European Environment Agency, Environmental Assessment Report Nr. 4, 2000.

Feldman G., N. Kuring, C. Ng, W. Esaias, C. McClain, J. Elrod, N. Maynard, D. Endres, R. Evans, J. Brown, S. Walsh, M. Carle, and G. Podesta, 1989. Ocean color: Availability of the global date set. EOS Trans. Amer. Geophys. Union, 70: 634-641.

Garcia-Gorriz E., and A. Stips, 2006. Physical and ecosystem model results for selected sub-basins of the Mediterranean sea. European Commission technical report, EUR 22620 EN.

Kilpatrick K.A, G.P. Podestá, and R. Evans, 2001. Overview of the NOAA/NASA advanced very high resolution radiometer Pathfinder algorithm for sea surface temperature and associated matchup database. J. Geophys. Res. C,106: $9179-9197$.

Longhurst A.R., S. Sathyendranath, T.Platt, and C. Caverhill, 1995. An estimate of global primary production in the ocean from satellite radiometer data. J. Plankt. Res., 17: 12451271.

McClain C., M. Cleave, G. Feldman, W. Gregg, S. Hooker, and N. Kuring, 1998. Science quality SeaWiFS data for global biosphere research. Sea Technology, 39: 10-16.

McGregor H.V., M. Dima, H.W. Fisher, and S. Mulitza, 2007. $20^{\text {th }}$-century increase in coastal upwelling off Northwest Africa. Science, 315: 637-639.

Miladinova S., and A. Stips, 2010. Sensitivity of oxygen dynamics in the water column of the Baltic Sea to external forcing. Ocean Sci. 6: 461-474.

Mueller J.L., 2000. SeaWiFS algorithm for the diffuse attenuation coefficient, K(490), using water-leaving radiances at 490 and $555 \mathrm{~nm}$. In S.B. Hooker (ed.), SeaWiFS postlaunch calibration and validation analyses, part 3, NASA Goddard Space Flight Centre, Greenbelt, Md., pp. 24-27.

O'Reilly J.E., S. Maritorena, D.A. Siegel, M.C. O'Brien, D.A. Toole, B.G. Mitchell, M. Kahru, M., F.P. Chavez, P. Strutton, G.F. Cota, S.B. Hooker, C.R. McClain, K.L. Carder, F.E. Mueller-Karger, L. Harding, A. Magnusson, D. Phinney, G.F. Moore, J. Aiken, K.R. 
Arrigo, R. Letelier, and M. Culver, 2000. Ocean color chlorophyll-a algorithms for SeaWiFS, OC2 and OC4: Version 4. NASA Technical Memorandum, 2000-206892, vol. 11, Chap. 2, 9-23, Eds., S.B. Hooker, \& E.R. Firestone, NASA-GSFC, Greenbelt, Maryland.

Peneva E., and A. Stips, 2005. Numerical simulations of Black Sea and adjoined Azov Sea, forced with climatological and meteorological reanalysis data. European Commission technical report, EUR 21504 EN.

Platt T., and S. Sathyendranath, 1988. Oceanic primary production: estimation by remote sensing at local and regional scales. Science, 241: 1613-1620.

Roy C., and C. Reason, 2001. ENSO related modulation of coastal upwelling in the eastern Atlantic. Prog. Oceanogr., 49: 245-255.

Stips A., K. Bolding, T. Pohlmann, and H. Burchard, 2004. Simulating the temporal and spatial dynamics of the North Sea using the new model GETM (general estuarine transport model). Ocean Dynamics , 54, 266-283.

Van Katwijk M.M., A.R. Bos, P. Kennis, and R. de Vries, 2010. Vulnerability to eutrophication of a semi-annual life history: A lesson learnt from an extinct eelgrass (Zostera marina) population. Biol. Conserv., 143: 248-254.

Vatsavai R., S. Shekhar, T. Burk, and S. Lime, 2006. UMN-MapServer: a highperformance, interoperable, and open source web mapping and geo-spatial analysis system. In: Proceedings of the $4^{\text {th }}$ International Conference on Geographic Information Science, GIScience 2006, Lecture Notes in Computer Science, vol. 4197. Springer, Munster, pp. 400-417. 